\title{
Satellite Solar-Induced Chlorophyll Fluorescence Reveals Heat Stress Impacts on Wheat Yield in India
}

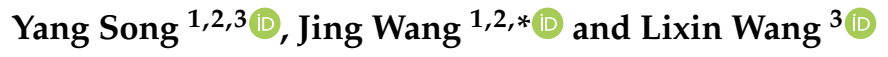 \\ 1 College of Resources and Environmental Sciences, China Agricultural University, Beijing 100193, China; \\ songyang0807@cau.edu.cn \\ 2 Key Laboratory of Remote Sensing for Agri-Hazards, Ministry of Agriculture and Rural Affairs, \\ Beijing 100083, China \\ 3 Department of Earth Sciences, Indiana University-Purdue University Indianapolis, Indianapolis, IN 46202, \\ USA; lxwang@iupui.edu \\ * Correspondence: wangj@cau.edu.cn
}

Received: 11 August 2020; Accepted: 7 October 2020; Published: 9 October 2020

check for updates

\begin{abstract}
With continued global warming, the frequency and severity of heat wave events increased over the past decades, threatening both regional and global food security in the future. There are growing interests to study the impacts of drought on crop. However, studies on the impacts of heat stress on crop photosynthesis and yield are still lacking. To fill this knowledge gap, we used both statistical models and satellite solar-induced chlorophyll fluorescence (SIF) data to assess the impacts of heat stress on wheat yield in a major wheat growing region, the Indo-Gangetic Plains (IGP), India. The statistical model showed that the relationships between different accumulated degree days (ADD) and reported wheat yield were significantly negative. The results confirmed that heat stress affected wheat yield across this region. Building on such information, satellite SIF observations were used to further explore the physiological basis of heat stress impacts on wheat yield. Our results showed that SIF had strong negative correlations with ADDs and was capable of monitoring heat stress. The SIF results also indicated that heat stress caused yield loss by directly impacting the photosynthetic capacity in wheat. Overall, our findings demonstrated that SIF as an effective proxy for photosynthetic activity would improve our understanding of the impacts of heat stress on wheat yield.
\end{abstract}

Keywords: global warming; remote sensing; multivariable linear regression; accumulated degree days; yield loss

\section{Introduction}

Wheat is one of the most widely grown crops in the world and plays a vital role in global food security. As a crop that is planted in autumn and harvested before the following summer, winter wheat (Triticum aestivum L.) prefers cooler temperatures. High temperatures can cause heat stress in wheat, especially during the grain-filling stage [1]. Excessive heat can accelerate leaf senescence and shorten grain-filling duration, resulting in yield loss [2-4]. With increasing risks of high temperatures under global warming, yield loss due to heat stress could be the main issue to the major wheat-producing regions [5]. For example, in the Indo-Gangetic Plains (IGP) of India, heat stress has already caused great yield loss in wheat over the past few decades [6-8]. In 2010, extreme heat stress affected this region and caused a significant reduction of wheat yields [9].

High temperature during the grain-filling period might slightly increase the grain-filling rates of wheat, but cannot completely compensate the disadvantage of shortened duration [4]. However, further damage would occur to the leaf photosynthetic apparatus when temperature exceeds a critical 
threshold [10-12]. For example, when air temperature is above $27^{\circ} \mathrm{C}$, the grain-filling rates of wheat tend to slow down and the number of sterile grains increase [7,13-15]. More serious impacts occur when air temperature is over $30^{\circ} \mathrm{C}$, resulting in greater yield loss [16]. Extreme heat stress (e.g., above $34^{\circ} \mathrm{C}$ ) further inhibit photosynthesis, reduce grain-filling rates, and accelerate crop senescence $[3,4]$. The occurrence of different levels of heat stress will become more uncertain with climate change, and will further threaten wheat production in the future $[13,17]$.

It is of importance to not only understand the mechanisms of heat stress on crop but to also improve the capability of monitoring the impacts. Crop simulation model is used to investigate crop physiological processes, in response to heat stress $[14,15]$. Although the crop model can provide a tool to quantify the influences of high temperatures in crops, the limitations of weather stations and uncertainties in simulation might lead to inaccurate results (e.g., over- or under-estimation of yield loss) for large-scale assessments [14]. Furthermore, the crop model would not accurately estimate the effects of heat stress on wheat, especially for extreme heat events [4,9].

Solar-induced chlorophyll fluorescence (SIF) is re-emitted at wavelength $650-800 \mathrm{~nm}$ as a by-product of photosynthesis [18-20]. As a unique proxy for photosynthetic activity, SIF has a closer relationship with photosynthetic capacity than vegetation indices (VIs) [9]. Recently, satellite-based SIF observations have become available, which provide more physiological information of vegetation from space [21]. For example, SIF can be derived from the Greenhouse gases Observing Satellite (GOSAT) of Japan Aerospace Exploration Agency (JAXA), the Orbiting Carbon Observatory-2 (OCO-2) of National Aeronautics and Space Administration (NASA), the Global Ozone Monitoring Instrument 2 (GOME-2), the TROPOspheric Monitoring Instrument (TROPOMI) of European Space Agency (ESA), and so on [20,22,23]. Using these satellite-based SIF observations, it is possible to detect vegetation photosynthetic activity and monitor crop growth conditions at large scales. Moreover, previous studies also showed that satellite SIF observations were highly correlated with the gross primary production (GPP) and were sensitive to respond to environmental stress [23-25]. Therefore, satellite-based SIF data is considered to be a better measurement for detecting photosynthesis and the responses of vegetation to environmental stress.

Although satellite-based SIF data is widely used to estimate GPP and monitor drought, its potential applications in agriculture require further verification. Satellite-based SIF data is highly correlated with aboveground crop biomass, which is directly related to crop yield [26]. It has great potential to predict crop yield [25-28]. Additionally, heat waves and drought events are likely to become more frequent with global warming, resulting in unpredictable yield loss [29]. Therefore, it would be an unprecedented opportunity to use satellite-based SIF data to improve our understanding of crop responses to climate change. For example, Song et al. [9] used satellite SIF observations to detect early response of winter wheat to heat stress in 2010, over the IGP. Their results implied that satellite SIF observations had great potential to monitor heat stress and assess the impacts on wheat yield at large scales. However, assessing only one extreme heat event could not fully reveal the process and mechanism of the impacts, and more quantitative studies should be conducted to further evaluate the impacts under different heat stress levels and estimate the yield loss.

In this study, we chose one representative wheat belt as our study area and conducted a comprehensive assessment of heat stress impacts using statistical model and satellite SIF observations. We hypothesized that SIF could be an effective proxy to reveal the impacts of heat stress on wheat yield. To test this hypothesis, we assessed the responses of SIF to different levels of heat stresses and the corresponding yield changes. The main objectives of this study were to (1) analyze the relationships between ADDs and wheat yield using statistical models, (2) demonstrate that SIF could improve the assessments of heat stress impacts on wheat yield, and (3) show the capability of SIF to monitor extreme heat events. 


\section{Materials and Methods}

\subsection{Study Area}

The study area was located in the Indo-Gangetic Plains (IGP), a major wheat-producing region in Northwest India, with abundant irrigation and fertilizer (Figure 1). In the IGP, winter wheat is usually planted from November to December and harvested during May of the following year. The variations in planting and harvest dates across this region are around 20 days, and heat stress mainly occurs during the grain-filling stage of wheat [4]. We conducted this study focusing on March and April, to ensure all districts were at the grain-filling stage and all data we used in this study could be well-matched in temporal resolution (i.e., monthly). The wheat harvested area with $0.083^{\circ}$ spatial resolution was identified via http://www.sage.wisc.edu [30,31].

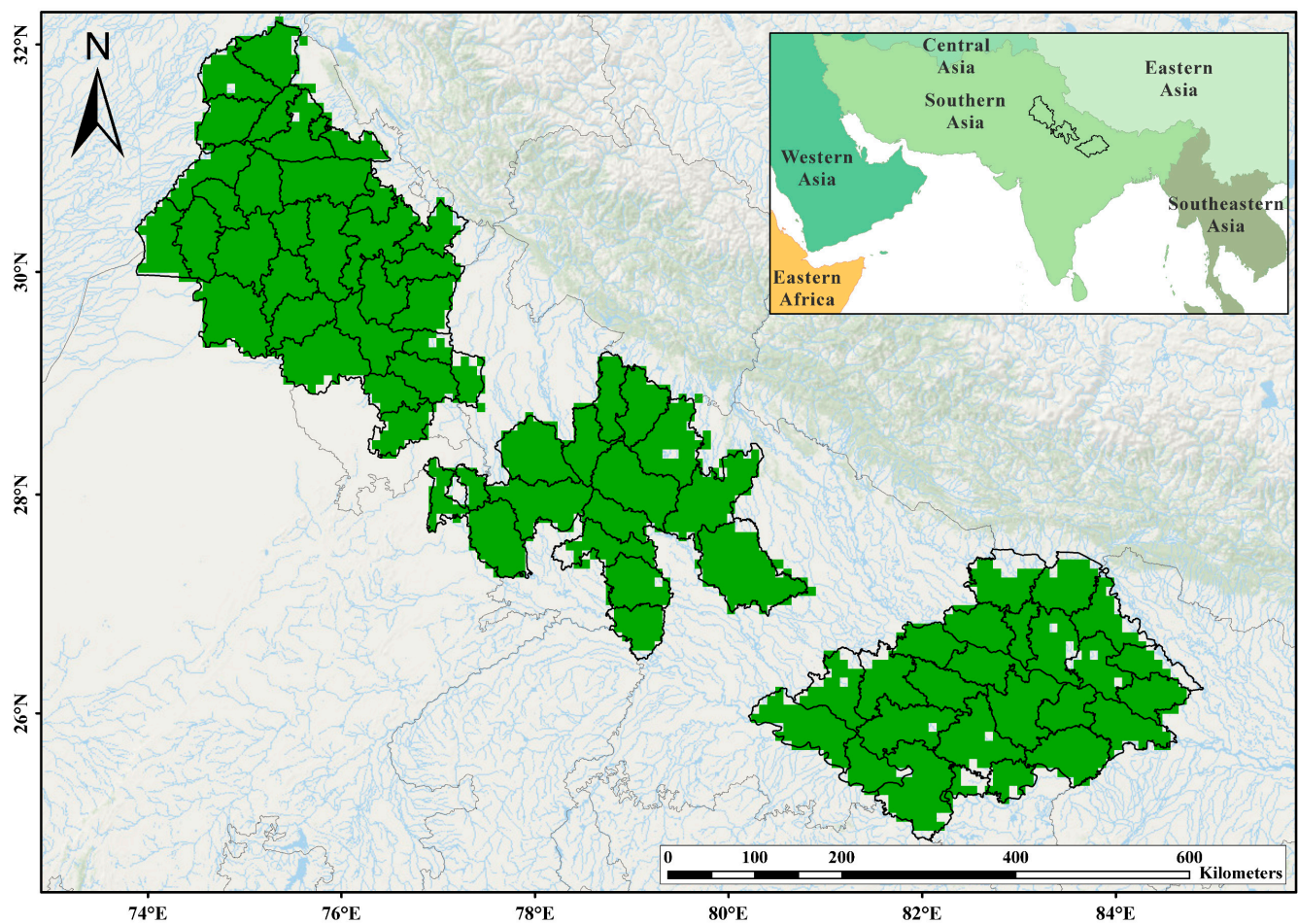

Figure 1. The study area in the Indo-Gangetic Plains (IGP) of India. Green pixels indicate grid cells with more than $40 \%$ wheat. The base map at the top-right corner is that of commonly recognized world regions.

\subsection{Meteorological and Yield Data}

Previous studies used daily mean temperature to compute the relationship between heat stress and crop yield $[9,13]$. However, daily mean temperature might underestimate the impacts of heat stress, because canopy temperature could be often higher than air temperature, especially when heat stress occurs [32]. Field observations indicated that the use of maximum temperature could improve the relationship significantly [14]. Therefore, the daily maximum temperature with $0.5^{\circ}$ spatial resolution was used in this study, which was obtained from Climate Prediction Center (CPC) Global Temperature data products (https://www.esrl.noaa.gov/psd/). The gridded rainfall data were the monthly average rain precipitation rate $\left(\mathrm{mm} \mathrm{s}^{-1}\right)$ obtained from the Global Land Data Assimilation System (GLDAS), with the Noah land surface model (https://ldas.gsfc.nasa.gov/) [33]. The annual district-level statistical reports of wheat yield were collected from Datanet India (https://www.indiastat.com/). Considering the yield loss caused by unseasonal rains and hailstorm in 2015, we did not use the data from 2015 in this study [34]. 


\subsection{Satellite-Based Solar-Induced Chlorophyll Fluorescence Data and Vegetation Indices}

Long-term satellite SIF observations could be derived from the Global Ozone Monitoring Instrument 2 (GOME-2) on board EUMETSAT's MetOp-A platform. These SIF observations contain information about canopy photosynthesis with $0.5^{\circ}$ spatial resolution at the global scale, from 2007 to present [35]. In this study, we used the monthly gridded GOME-2 SIF dataset from GOME_F SIF product to conduct our analysis instead of the raw data [36]. The product (level 3, version 2.8.0) was performed in the 734-758 nm spectral window (peak of the far-red chlorophyll fluorescence at $740 \mathrm{~nm}$ ) and had various filtering applied for better quality $[37,38]$. The dataset was composited by daily-averaged SIF estimates, based on a single observation. The daily-averaged SIF estimates were normalized by the cosine of the solar zenith angle to eliminate the effect of variation in photosynthetically active radiation (PAR), with hours. The dataset and detailed information are available via https://avdc.gsfc.nasa.gov/pub/data/satellite/MetOp/GOME_F/. Moreover, the OCO-2 SIF product with $0.05^{\circ}$ spatial resolution (https://doi.org/10.3334/ORNLDAAC/1696/) was used to compare with the coarse-resolution GOME-2 SIF product. The OCO-2 SIF data had high temporal-spatial resolution, but could be limited by its short time-series (from 2014 to present). In addition, we also used the VI product (MOD13C2) to conduct this study (https://lpdaac.usgs.gov/products/mod13c2v006/). Normalized Difference Vegetation Index (NDVI) and Enhanced Vegetation Index (EVI) from this product were used to compare with the SIF results, for understanding the advantages and disadvantages of SIF and VIs in assessing heat stress impact on wheat and in estimating the yield loss.

\subsection{Analysis}

This study focused on impacts of heat stress on wheat yield in the IGP during 2008-2018, except for the year 2015. The data of 2015 was not used in our analysis if not specifically mentioned. To match the temporal resolution of GOME-2-based SIF observations and the spatial resolution of wheat planting area, all datasets were resampled and aggregated into monthly composites, at approximately $0.083^{\circ}$ spatial resolution. The critical temperatures during the grain-filling stage of wheat are difficult to identify. For the present analysis, we chose the threshold values from some previous studies, based on field experiment and crop model $[4,14]$. Meanwhile, we also considered the uncertainty caused by different wheat cultivars. Then, the gradient threshold values were defined as $27^{\circ} \mathrm{C}, 30^{\circ} \mathrm{C}$, and $34^{\circ} \mathrm{C}$, to calculate the accumulated degree days (ADD), respectively. The ADD above different daily maximum temperatures were calculated to represent different levels of heat stress. The ADD is defined as follows:

$$
\begin{aligned}
& \mathrm{ADD}=\sum_{t=1}^{N} \mathrm{DD}_{t}
\end{aligned}
$$

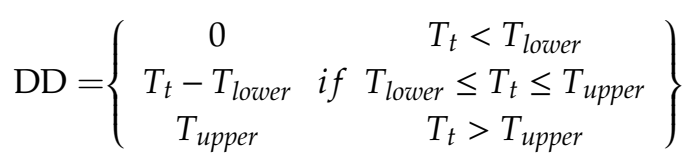

where $t$ represents the daily time step, $N$ is the total number of days in the month, DD represents degree days, $T_{\text {lower }}$ and $T_{\text {upper }}$ are the different lower and upper limit temperatures, respectively, in different accumulated temperature ranges. In this study, $\mathrm{T}_{\text {lower }}$ was set to $0^{\circ} \mathrm{C}, 27^{\circ} \mathrm{C}, 30^{\circ} \mathrm{C}$, and $34{ }^{\circ} \mathrm{C}, \mathrm{T}_{\text {upper }}$ was set to $27^{\circ} \mathrm{C}, 30^{\circ} \mathrm{C}, 34^{\circ} \mathrm{C}$, and $\infty$. We computed the ADD over $0{ }^{\circ} \mathrm{C}, 27^{\circ} \mathrm{C}, 30^{\circ} \mathrm{C}$, and $34^{\circ} \mathrm{C}\left(\mathrm{T}_{\text {lower }}\right.$

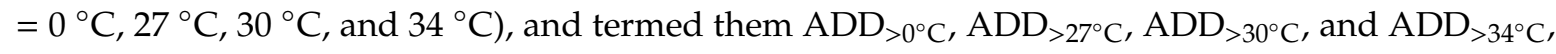
respectively. It was noted that all daily maximum temperatures in March-April were not below $0{ }^{\circ} \mathrm{C}$, across our study area, and therefore, $\mathrm{ADD}_{>0^{\circ} \mathrm{C}}$ was also defined as the total $\mathrm{ADD}$. The different $\mathrm{ADDs}$ (i.e., $\mathrm{ADD}_{>0^{\circ} \mathrm{C}}, \mathrm{ADD}_{>27^{\circ} \mathrm{C}}, \mathrm{ADD}_{>30^{\circ} \mathrm{C}}$, and $\mathrm{ADD}_{>34^{\circ} \mathrm{C}}$ ) represent different levels of heat stress.

To quantify the impacts of different heat stresses on wheat yield, a multivariable linear regression was applied to each ADD:

$$
\text { Yield }_{d, y}=\beta_{0}+\beta_{1} \mathrm{ADD}_{\text {lower }}+\beta_{R} \text { Rainfall }+\varepsilon
$$


where Yield ${ }_{d, y}$ is wheat yield in district $d$ and year $y, \mathrm{ADD}_{\text {lower }}$ represents the accumulated degree days of March-April in the corresponding district and year, over different lower limit temperatures (i.e., $\mathrm{ADD}_{>27^{\circ} \mathrm{C}}, \mathrm{ADD}_{>30^{\circ} \mathrm{C}}$, and $\mathrm{ADD}_{>34^{\circ} \mathrm{C}}$ ), Rainfall represents the average rain precipitation rate in March-April, $\beta_{0}$ is the intercept, $\beta_{1}$ and $\beta_{R}$ are the regression coefficients, $\varepsilon$ is the residual. Wheat in the IGP is well-irrigated, so water stress was not considered in this study. Rainfall was included in the model because it could alleviate heat stress and offset some negative effects on wheat yield [4]. We also calculated the variance inflation factor (VIF) to test co-linearity in our multiple regressions. SIF was regarded as a proxy for photosynthetic activity. In this study, a simple linear regression based on satellite SIF observations was used to estimate wheat yield:

$$
\text { Yield }_{d, y}=\beta_{0}^{\prime}+\beta_{1}^{\prime} \mathrm{SIF}+\varepsilon^{\prime}
$$

where Yield w $_{1, y}$ is wheat yield in district $d$ and year $y$, SIF represents the mean satellite SIF observations of March-April in corresponding district and year, $\beta_{0}^{\prime}$ is the intercept, $\beta_{1}^{\prime}$ is the regression coefficient, and $\varepsilon^{\prime}$ is the residual. Moreover, we also conducted another multivariable linear regression for assessing the contributions of climatic factors on improving the performance and accuracy of yield estimations:

$$
\text { Yield }_{d, y}=\beta_{0}^{\prime \prime}+\beta_{1}^{\prime \prime} \mathrm{SIF}+\beta_{2}^{\prime \prime} \mathrm{ADD}_{>0} \mathrm{C}+\beta_{R}^{\prime \prime} \text { Rainfall }+\varepsilon^{\prime \prime}
$$

where $\beta_{0}^{\prime \prime}$ is the intercept, $\beta_{1}^{\prime \prime}, \beta_{2}^{\prime \prime}$, and $\beta_{R}^{\prime \prime}$ is the regression coefficients, and $\varepsilon^{\prime \prime}$ is the residual. The normalized anomalies of variables were calculated on a pixel-by-pixel basis to compare the spatial-temporal variations in ADDs, rainfall, and SIF:

$$
\operatorname{var}^{\prime}=\left(\operatorname{var}_{\mathrm{t}}-\overline{\operatorname{var}}\right) / \sigma_{\mathrm{var}}
$$

where var' represents the normalized anomalies of variables, var $_{t}$ represents the original value of variables at time $t, \overline{\mathrm{var}}$ and $\sigma_{\mathrm{var}}$ represent the mean and standard deviation of variables during 2008-2018 (except the year 2015), respectively.

\section{Results}

\subsection{The Heat Stress across the IGP during the Wheat Grain-Filling Stage}

This study analyzed the relationships between ADDs and wheat yield using statistical models, to assess the impacts of heat stress on wheat yield across the IGP. The total $\mathrm{ADD}$ (i.e., $\mathrm{ADD}_{>0^{\circ} \mathrm{C}}$ ) across this region during the wheat grain-filling stage was high (Figure 2a). Wheat in this region suffered from high temperature over the past 10 years. Our results showed that the total ADD had a negative correlation with yield (Figure $2 b$ ). On the contrary, rainfall was conducive to wheat growth and had a positive effect on yield (Figure 2c). In general, excessive temperature and heat would stunt wheat growth and result in yield loss. Although rainfall could alleviate heat stress by decreasing leaf and land surface temperatures (Figure 2d), it would still fail to prevent yield loss from increasing ADD. 

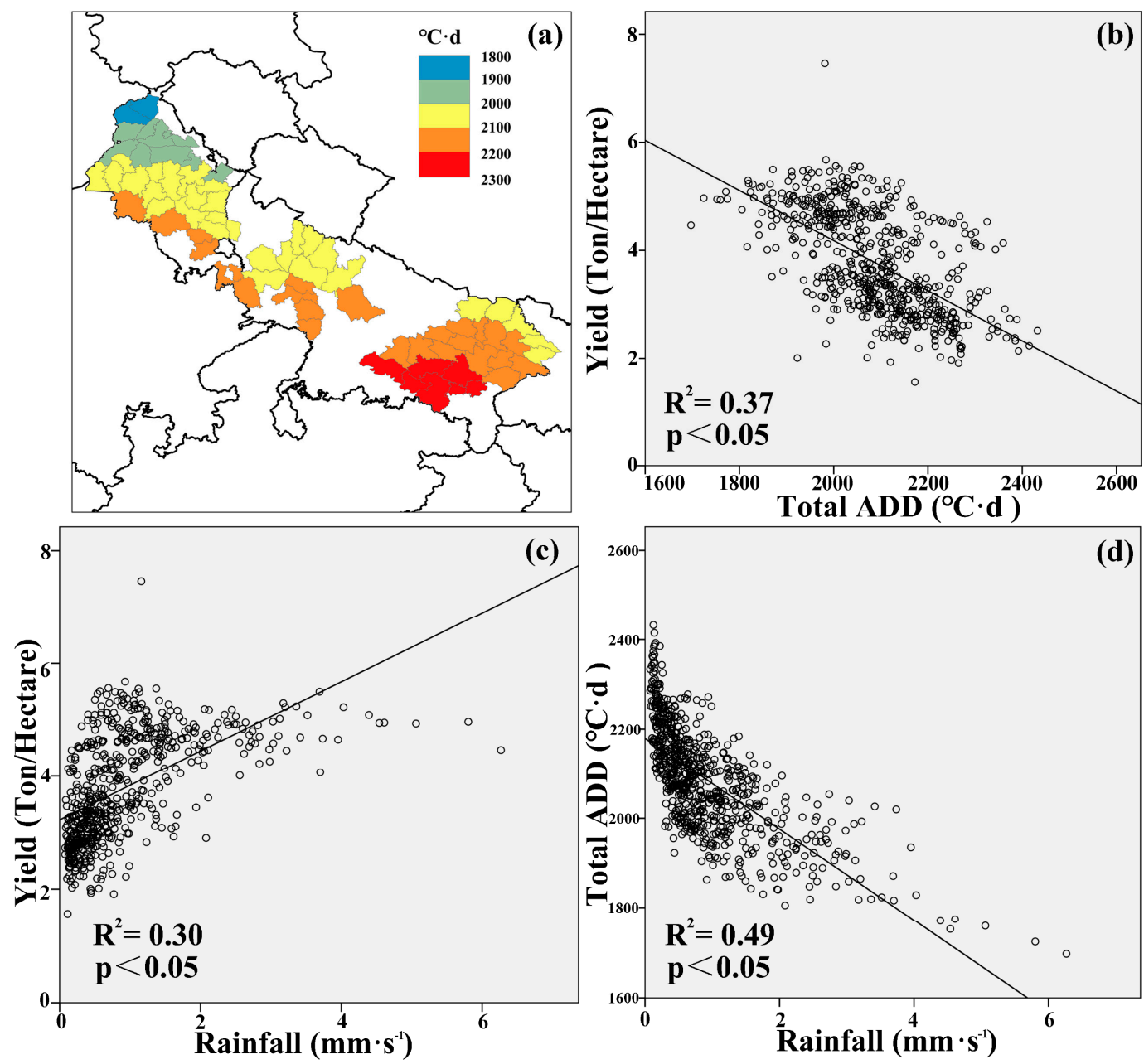

Figure 2. The spatial map of the total accumulated degree days (ADD) during the wheat grain-filling stage across the IGP (a), and the relationships between (b) the total ADD and yield, (c) rainfall and yield, and (d) rainfall and the total ADD at the district scale.

Each regression was carried out to assess the impacts of rainfall and different ADD on wheat yield.

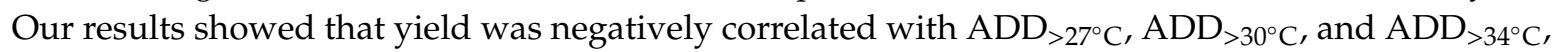
while it had a positive correlation with rainfall (Figure 3). Different heat stresses (i.e., ADDs) can impact wheat growth to varying extent. All regressions and their variables were statistically significant $(\mathrm{p}<0.05)$. In each regression, the Pearson correlation coefficients between rainfall and ADD (i.e.,

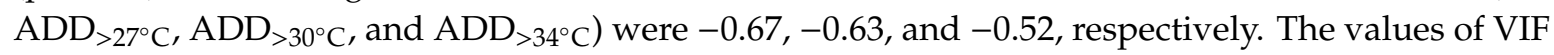
showed that there was almost no co-linearity $(0<\mathrm{VIF}<2)$ in our regression equations. Our findings demonstrated that heat stress seriously affected wheat growth during the grain-filling stage and could be one of the main factors of yield loss across the IGP. The climate variables could explain the phenomenon of yield loss, but it would be difficult to evaluate the underlying physiological basis (e.g., photosynthesis) of heat stress impacts on wheat yield, at large scales. 


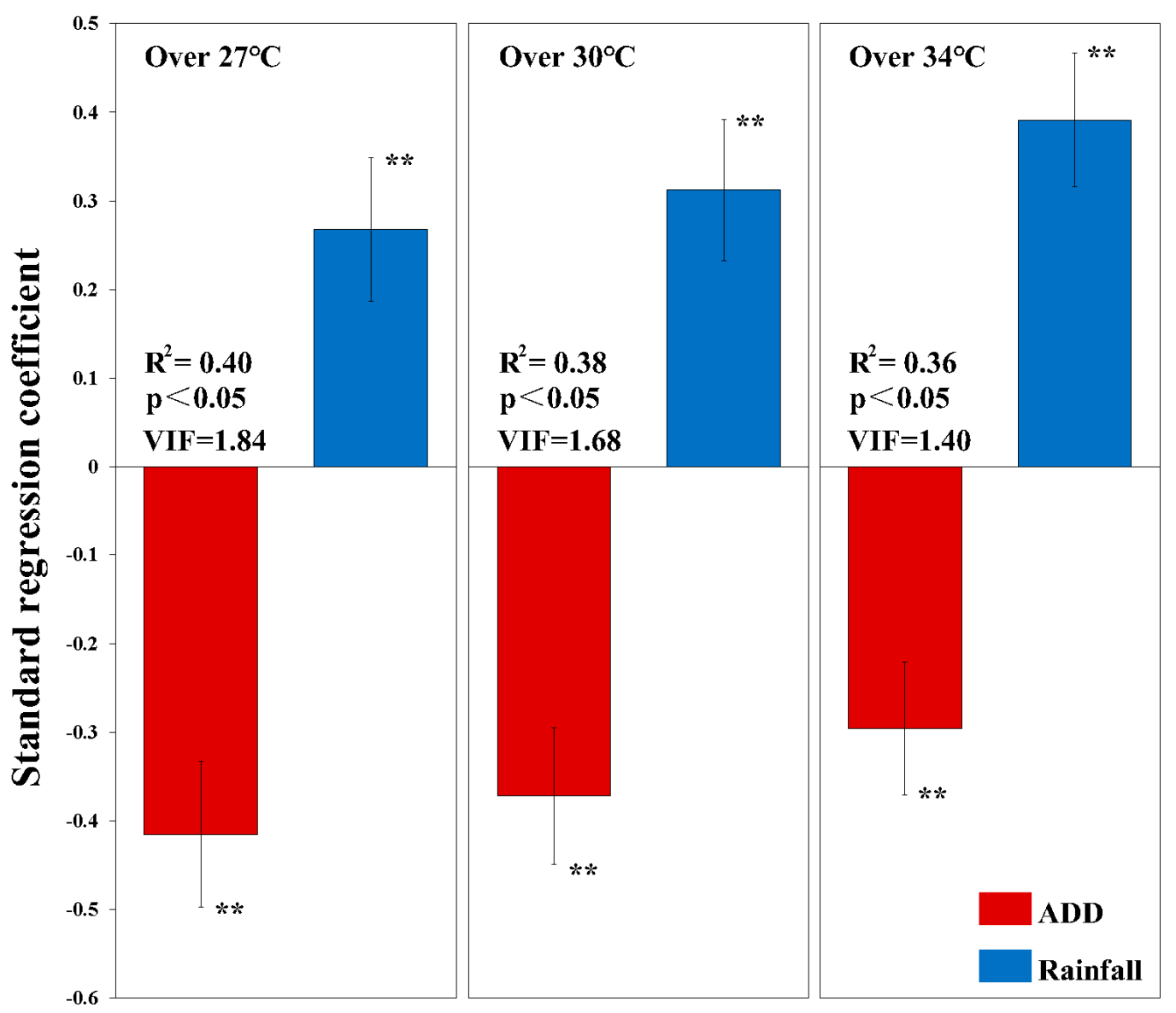

Figure 3. Estimated coefficients for ADD and rainfall in a standard regression to quantify the impacts of different heat stresses (over $27^{\circ} \mathrm{C}, 30^{\circ} \mathrm{C}$, and $34{ }^{\circ} \mathrm{C}$ ) on wheat yield. Error bars indicate 5-95\% confidence interval and stars indicate statistical significance $(* *: p<0.05)$.

\subsection{Using SIF to Assess Heat Stress and Its Impacts on Wheat}

It could be insufficient to only use climate-related variables to monitor crop growth and predict yield. We need more physiological measurements to assess them. Our results showed that the relationships between SIF and ADDs were significantly negative $(\mathrm{p}<0.05)$ (Figure 4). Heat stress could cause a decline in SIF by weakening photosynthetic activity in wheat. The variations in actual photosynthetic capacity could be one main physiological mechanism of crops in response to heat stress. Therefore, our findings indicated that SIF could be used to reveal the physiological processes under heat stress and assess the impacts on wheat growth. Additionally, using NDVI and EVI, we could also monitor heat stress and assess the impacts on wheat. The results of NDVI and EVI were similar, but had a few differences with those of SIF in spatial distribution (Supplementary Material, Figure S1). 


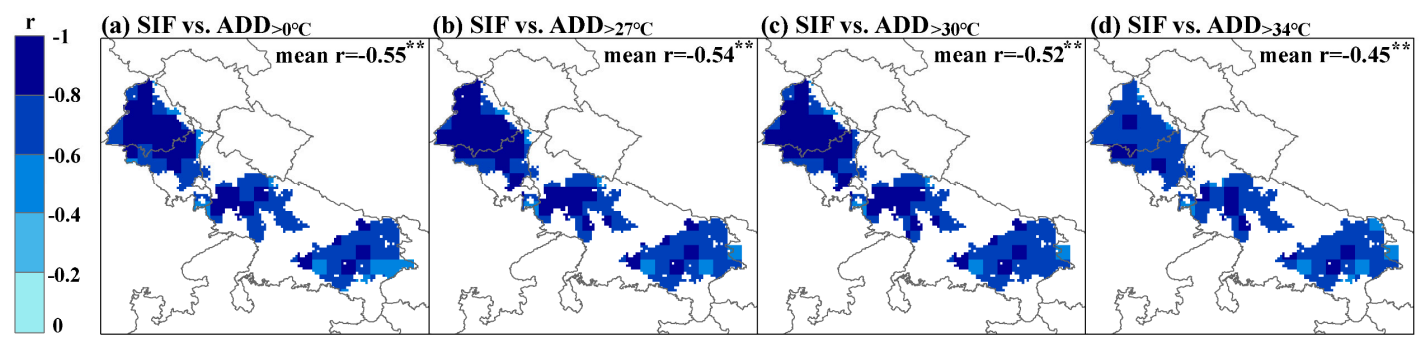

Figure 4. Pearson correlation coefficients (r) between the mean solar-induced chlorophyll fluorescence (SIF) and ADD over (a) $0{ }^{\circ} \mathrm{C}$, (b) $27^{\circ} \mathrm{C}$, (c) $30^{\circ} \mathrm{C}$, and (d) $34{ }^{\circ} \mathrm{C}$ in March-April. Colored pixels are statistically significant $(\mathrm{p}<0.05)$. The mean $\mathrm{r}$ is the average of the correlation coefficients at the district scale and stars indicate statistical significance $(* *: p<0.05)$.

The spatial distribution of multiyear mean yield based on SIF (Figure 5a) was consistent with the district-level statistical reports (Figure $5 b$ ). The simple linear regression using SIF data performed better result $\left(R^{2}=0.56, p<0.05\right)$ than only the statistical model, when using climatic factors. SIF had a negative response to ADDs, but had a positive relationship with yield. In other words, SIF as an intermediary factor was related to both heat stress and yield. The variations in yield caused by heat stress could accurately be estimated by SIF. Therefore, our findings demonstrated that heat stress could impact wheat yield by directly declining photosynthetic capacity. In the SIF model, the added climate variables could only slightly improve the accuracy of yield estimation $\left(R^{2}=0.59, p<0.05\right)$.
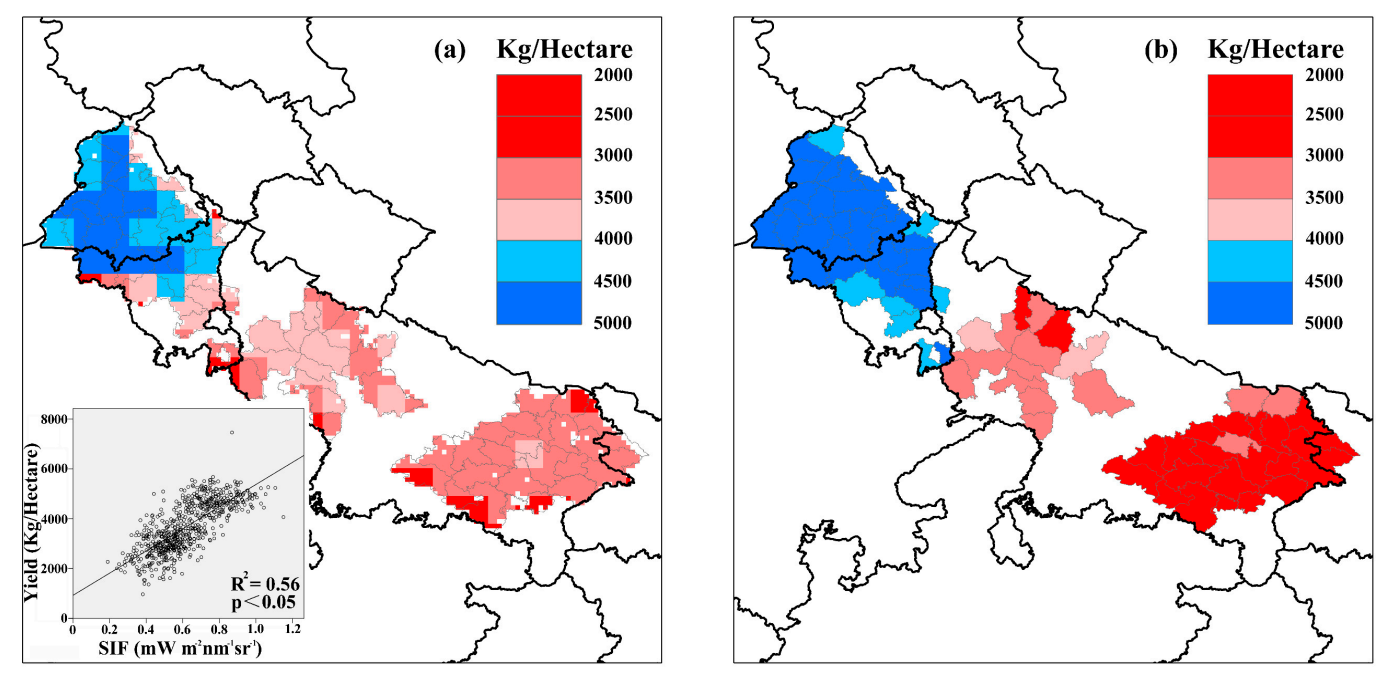

Figure 5. Spatial distributions of winter wheat yield based on (a) SIF and (b) district-level statistical reports. The scatter plots in the bottom-left corner show the relationship between the yield and SIF at the district scale, each dot represents the mean SIF in March-April and statistical yield, for each district and one year.

\subsection{The Capability of SIF to Monitor the Extreme Heat Event}

In 2010, heat waves spread over the whole region with strong impacts on wheat. In particular,

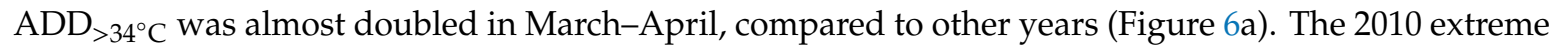
heat event gradually evolved in February and quickly expanded until the wheat was harvested. Extreme heat occurred severely and was more widespread across the IGP, especially in March and April. The total ADD was extremely high $(>2 \sigma)$ when the heat stress peaked in April (Figure $6 \mathrm{~b}$ ). Meanwhile, the monthly average rainfall had a significant decrease both in March and April (Figure 6c). The negative rainfall anomalies could further aggravate heat stress in wheat. However, higher rainfall in May could offset some negative impacts of extreme heat and compensate some yield loss. In general, extreme heat would cause more yield loss in 2010 than usual. Our results showed that the interaction 
of heat stress and rainfall would lead to the spatial-temporal variations in SIF and yield. For example, the spatial-temporal variations in SIF showed discontinuous and heterogeneous anomalies (Figure 6d). Varying degrees of decrease in SIF were detected over the IGP, with the largest negative anomalies less than $-2 \sigma$. However, there were also some positive anomalies of SIF in each month. The positive and negative anomalies could be converted to each other with time. Our findings showed that satellite SIF observations could inform more details about photosynthetic activity at large scales. The dynamic changes in SIF could reveal the responses of photosynthetic processes in wheat to extreme heat stress.

(a) Extreme heat event in 2010

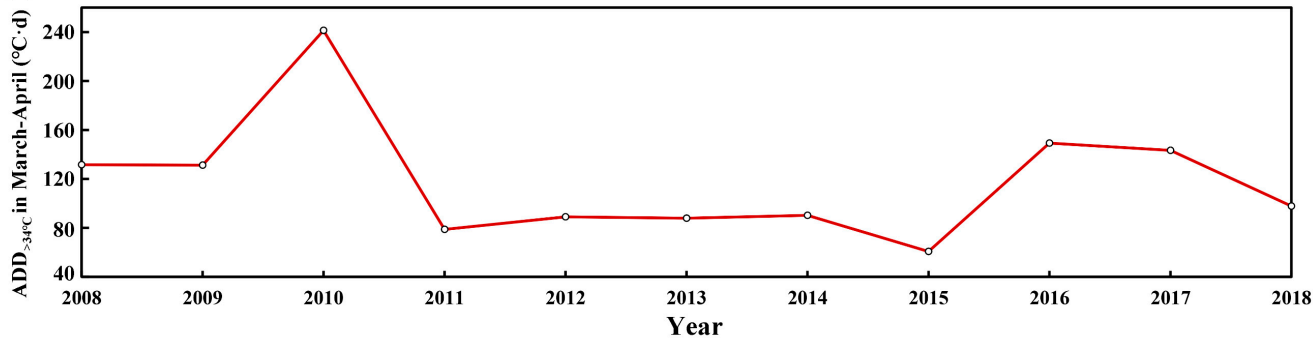

(b) Normalized anomalies of monthly total ADD

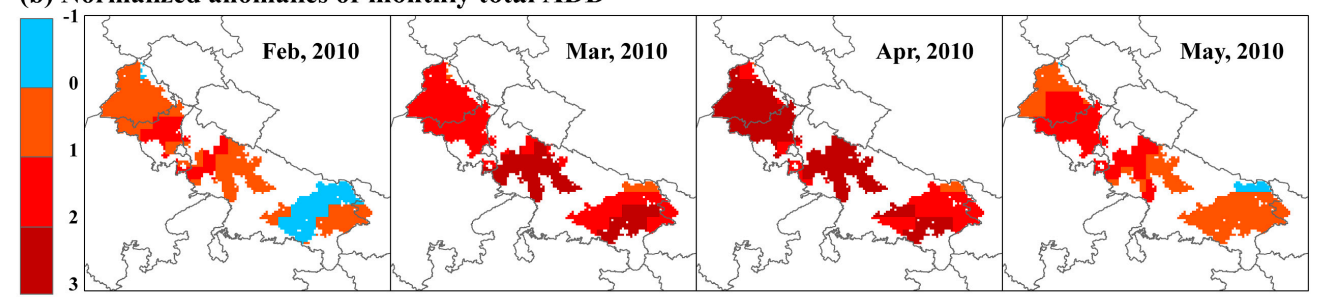

(c) Normalized anomalies of monthly total rainfall

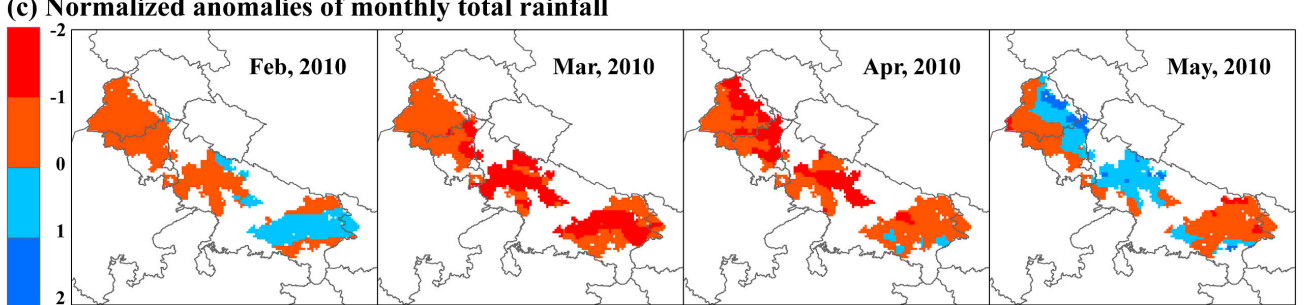

(d) Normalized anomalies of SIF

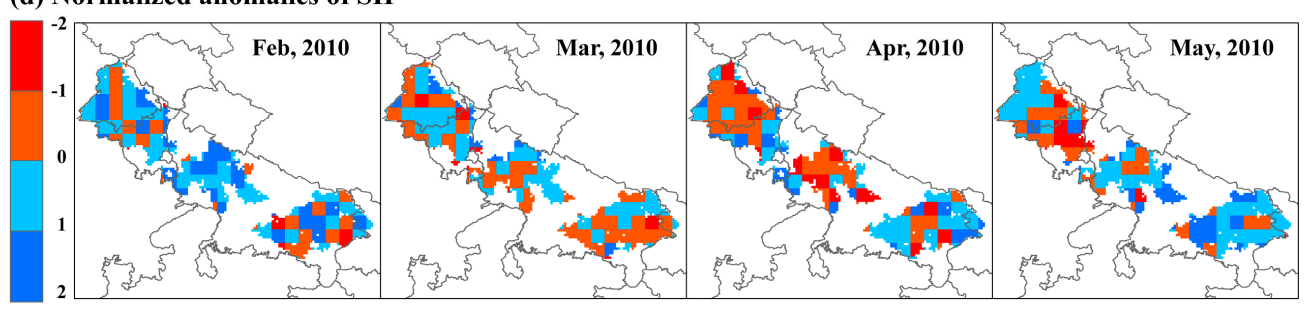

Figure 6. The 2010 extreme heat event in the IGP. (a) Interannual variations of $\mathrm{ADD}_{>34^{\circ} \mathrm{C}}$ in March-April. Spatial distribution of (b) normalized anomalies of the total ADD, (c) normalized anomalies of monthly average rainfall, (d) and normalized anomalies of SIF from February to May in 2010.

The relationship between yield and SIF was significant under extreme heat stress $\left(\mathrm{R}^{2}=0.68\right.$, $\mathrm{p}<0.05)$. The spatial distribution of yield loss based on SIF showed great spatial heterogeneity in 2010 (Figure 7a). Even within one district, different cultivars or agronomic management measures could lead to different wheat yields, especially under extreme heat stress. Although the relationship between SIF and yield was good, the coarse-resolution of the GOME-2 SIF product would limit the performance. Compared to the district-level statistical reports (Figure 7b), the SIF results showed mosaic-like and irregular yield estimates. 

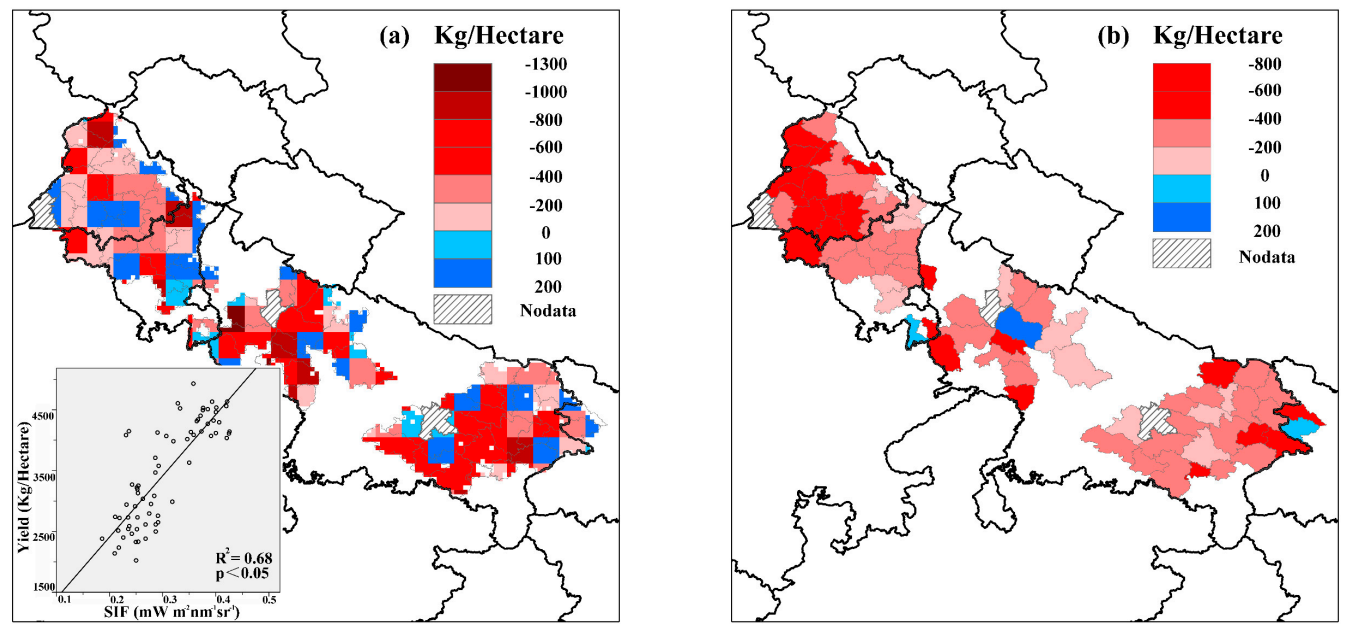

Figure 7. Spatial distributions of 2010 winter wheat yield loss based on (a) SIF and (b) district-level statistical reports. The scatter plots in the bottom-left corner show the linear regression model that describes the relationship between the yield and SIF, each dot represents the mean SIF in March-April and statistical yield for each district in 2010.

Overall, satellite-based SIF had the capability to monitor the response of wheat to heat stress. The variation in SIF could reveal spatial-temporal dynamic of photosynthetic activity in wheat and the impacts of heat stress on yield. The process of how heat stress impacts wheat yield by directly declining photosynthetic capacity is becoming clearer in an extreme heat event. With long time-series, the GOME-2 SIF product has the potential to solve more climate change issues, but its low spatial resolution would limit the applications at the regional scale. Our findings suggest that satellite SIF observations could diagnose the impact of heat wave on wheat yield, and the performance would be improved by more fine-resolution SIF products in the future.

\section{Discussion}

The effect of climate change on crop yield is a rapidly growing research field. In this study, we focused on assessing the impacts of different heat stresses on wheat yield. The accumulation of daily maximum temperature, termed ADD, was used to represent the heat stress in wheat. Previous studies indicated that uses of daily maximum temperature instead of daily mean temperature could significantly improve the relationship between heat stress and relative yield loss [2,14,39]. Maximum air temperature could be closer to the actual canopy temperature under heat stress [32,40]. Additionally, since high temperature could be one of the main limiting factors for the wheat production of the IGP [4,9], we did not further analyze other climate variables (e.g., soil moisture, evapotranspiration, vapor pressure deficit, and so on). Upon further analysis, the extent to which heat stress affects wheat yield in the IGP was demonstrated through statistical models. Although our results showed that rainfall could offset some negative impacts of heat stress on wheat, high temperature would still cause yield loss. This study did not consider water stress, since wheat is well irrigated across this region [17]. Instead, we assessed the effects of rainfall on decreasing leaf and land surface temperatures in our regression model. Our findings suggest that continued warming affected the wheat production of the IGP, and adaptation strategies are necessary to be taken to prevent more loss in the future [3].

Satellite SIF observations were used to reveal the heat stress impacts on photosynthetic activity and estimate yield loss. The SIF results extended our statistical model findings to pixel scale, with strong physiological significance. Our study demonstrated that SIF could assess the impacts of heat stress on wheat yield, and the results were consistent with previous studies [9,25,41]. Meanwhile, the spatial-temporal variation in SIF showed significant and quick responses to heat stress. Our results indicated that SIF could capture the spatial-temporal dynamics of heat stress. Previous studies proved that SIF could be a direct and functional proxy for photosynthetic activity [42-45]. Therefore, it could 
be a good choice to use SIF to quantify the impacts of heat stress on wheat yield. In our study, SIF was regarded as an intermediary factor to represent actual photosynthesis under heat stress. Our results showed that satellite SIF observations could be used to assess the capability of monitoring heat stress, especially in extreme heat events. In general, our findings suggest that SIF could be a bridge to explore the relationship between heat stress and crop yield.

The monthly gridded SIF dataset we used in this study was the GOME-2 product composited by the estimated daily-averaged SIF values. This dataset was also normalized by PAR, which could be used to indicate the effective fluorescence yield and eliminate the effect of variation in PAR [28,41]. Some previous studies also used the absorbed photosynthetically active radiation (APAR) to further eliminate the effect of APAR on SIF [9,22]. The SIF normalized by APAR (referred to as SIF yield) could be identified to indicate photosynthetic efficiency of plants. Actually, heat stress could remarkably reduce both photosynthetic capacity and efficiency, and even change the canopy structure. Although our results showed the negative response of SIF to heat stress at large scales, more studies are needed to explore the impact and process at the canopy scale. Additionally, the sensor degeneration of GOME-2 could create some potential uncertainties [45,46], which also needs more attention in future studies.

Although Song et al. [9] showed that GOME-2 SIF has a better performance of monitoring heat stress in wheat, high spatial and temporal resolution of VIs could provide similar and even better results. In this study, the spatial distribution and spatial-temporal dynamic of VIs (Figure S1, S2) showed some differences with those of SIF. The responses of VIs to heat stress could have a potential hysteresis effect. However, the SIF data we used was retrieved from a far-red band, which could represent the instantaneous state of photosynthetic capacity in wheat. The performances of VIs and SIF should be assessed by considering specific objective and study area. It should be careful to directly compare them, since their retrieval and production methods are different. Moreover, we also used VIs to estimate wheat yield to compare the differences with those results of SIF (Figure S3). We conducted the yield estimations with longer time-series (2008-2014, 2016-2018) than the previous study (2008-2013) [9]. The results showed that NDVI and EVI could capture the interannual variation in wheat yield better than GOME-2 SIF, which was opposite to their results [9]. Considering the differences of data source and processing algorithm between ours and theirs, the performance of yield estimation using VIs or SIF should be further verified and discussed.

For exploring the performance of yield estimation using high-resolution SIF data and informing the potential limitation of using the coarse-resolution GOME-2 SIF product, we conducted a comparison with the recent OCO-2 SIF product [47]. The results showed that the yield estimations based on four satellite data were as good as each other (Figure S4). Although we tried to match the data of the wheat harvested area with high resolution SIF data for improving yield estimation, the high-resolution OCO-2 SIF data could not perform better than coarse-resolution GOME-2 SIF product. The effect of mixed pixel could still cause error and uncertainty of relationship between satellite-based SIF and statistical yield. Moreover, the selected study period could also affect the results. In this comparison, the OCO-2 SIF with short time-series could not show the complete performance of yield estimation. During 2016-2018, the interannual variations in yield for each district were obvious (Table S1), but those in SIF were not (Table S2). We assessed the relationships between ADDs and yield using a simple linear regression. The results showed that the negative impacts of ADDs on yield could be weaker during 2016-2018 than those during 2008-2018 (Table S3). The variations in yield could be caused by some other factors, and might not be a result of the decline of photosynthetic capacity. Our findings suggest that the yield loss, which was not caused by the limitation of photosynthesis, would not be detected or estimated by SIF data. Overall, higher resolution SIF product with long time-series would be needed for further assessing and improving the performance of yield estimation.

For application of SIF in agriculture, previous studies demonstrated that SIF could capture spatial-temporal variation in environmental stress and was able to estimate crop yield $[9,25,26]$. Our results also confirmed that satellite SIF observations had a high sensitivity to heat stress and a good correlation with wheat yield. On the one hand, heat stress could decline photosynthetic capacity 
and weaken vegetation fluorescence [48]. On the other hand, heat stress could also speed up wheat senescence and shorten the growing period [4]. Both reasons could lead to the reduction of SIF in March-April and result in yield loss. Overall, our findings showed that satellite SIF observations have its unique sensitivity to the impacts of environmental stress on crop. In future, more studies and satellite-based SIF products are needed for further extending its application and improving its results $[49,50]$.

\section{Conclusions}

Using statistical model and satellite SIF observations, this study assessed the impacts of heat stress on wheat yield in the IGP, India. The results, based on statistical models, showed that ADDs have negative correlations with wheat yield, and then demonstrated that heat stress could be one of the main factors of yield loss. On this basis, further analysis indicated that SIF has physiological meaning and is useful to reveal the relationship between heat stress and yield. SIF as an effective proxy for photosynthetic activity could be used to detect the variations in wheat growth and the responses to different heat stresses. Our results demonstrated that heat stress could impact wheat yield by directly declining photosynthetic capacity. SIF could be used to improve both the results of monitoring heat stress and estimating crop yield. Overall, our study quantified the impacts of heat stress on wheat yield and revealed its physiological pathway. As novel spaceborne data, satellite SIF observations showed its great potential of monitoring crop growth and assessing the impacts of heat stress on yield.

Supplementary Materials: The following are available online at http://www.mdpi.com/2072-4292/12/20/3277/s1.

Author Contributions: Conceptualization, Y.S., J.W., and L.W.; Formal Analysis, Y.S.; Investigation, Y.S. and J.W.; Methodology, Y.S., J.W., and L.W.; Writing-Original Draft Preparation, Y.S.; Writing-Review \& Editing, J.W. and L.W. All authors have read and agreed to the published version of the manuscript.

Funding: This research was funded by the National Key Research and Development Program of China, grant number: 2016YFD0300105.

Acknowledgments: We are grateful to the anonymous reviewers and editors whose comments greatly improved this manuscript. The authors would like to acknowledge the NOAA/OAR/ESRL PSD for providing the CPC Global Temperature data products and the SAGE of UW-Madison for the harvested area dataset. Y.S. would like to thank Chiu for English language editing and proofreading. All data used in this study are available by request (songyang0807@cau.edu.cn).

Conflicts of Interest: The authors declare no conflict of interest.

\section{References}

1. Wardlaw, I.F.; Wrigley, C.W. Heat Tolerance in Temperate Cereals-An Overview. Aust. J. Plant Physiol. 1994, 21, 695-703. [CrossRef]

2. Dias, A.S.; Lidon, F.C. Evaluation of Grain Filling Rate and Duration in Bread and Durum Wheat, under Heat Stress after Anthesis. J. Agron. Crop Sci. 2009, 195, 137-147. [CrossRef]

3. Asseng, S.; Foster, I.; Turner, N.C. The impact of temperature variability on wheat yields. Glob. Chang. Biol. 2011, 17, 997-1012. [CrossRef]

4. Lobell, D.B.; Sibley, A.; Ortiz-Monasterio, J.I. Extreme heat effects on wheat senescence in India. Nat. Clim. Chang. 2012, 2, 186-189. [CrossRef]

5. Asseng, S.; Ewert, F.; Martre, P.; Rotter, R.P.; Lobell, D.B.; Cammarano, D.; Kimball, B.A.; Ottman, M.J.; Wall, G.W.; White, J.W.; et al. Rising temperatures reduce global wheat production. Nat. Clim. Chang. 2015, 5, 143-147. [CrossRef]

6. Gupta, R.; Somanathan, E.; Dey, S. Global warming and local air pollution have reduced wheat yields in India. Clim. Chang. 2017, 140, 593-604. [CrossRef]

7. Sun, Q.H.; Miao, C.Y.; Hanel, M.; Borthwick, A.G.L.; Duan, Q.Y.; Ji, D.Y.; Li, H. Global heat stress on health, wildfires, and agricultural crops under different levels of climate warming. Environ. Int. 2019, 128, 125-136. [CrossRef] [PubMed]

8. Zaveri, E.; Lobell, D.B. The role of irrigation in changing wheat yields and heat sensitivity in India. Nat. Commun. 2019, 10. [CrossRef] 
9. Song, L.; Guanter, L.; Guan, K.Y.; You, L.Z.; Huete, A.; Ju, W.M.; Zhang, Y.G. Satellite sun-induced chlorophyll fluorescence detects early response of winter wheat to heat stress in the Indian Indo-Gangetic Plains. Glob. Chang. Biol. 2018, 24, 4023-4037. [CrossRef]

10. Alkhatib, K.; Paulsen, G.M. Mode of High-Temperature Injury To Wheat during Grain Development. Physiol. Plant. 1984, 61, 363-368. [CrossRef]

11. Al-Khatib, K.; Paulsen, G.M. High-temperature effects on photosynthetic processes in temperate and tropical cereals. Crop Sci. 1999, 39, 119-125. [CrossRef]

12. Porter, J.R.; Gawith, M. Temperatures and the growth and development of wheat: A review. Eur. J. Agron. 1999, 10, 23-36. [CrossRef]

13. Teixeira, E.I.; Fischer, G.; van Velthuizen, H.; Walter, C.; Ewert, F. Global hot-spots of heat stress on agricultural crops due to climate change. Agric. For. Meteorol. 2013, 170, 206-215. [CrossRef]

14. Rezaei, E.E.; Siebert, S.; Ewert, F. Impact of data resolution on heat and drought stress simulated for winter wheat in Germany. Eur. J. Agron. 2015, 65, 69-82. [CrossRef]

15. Feng, P.Y.; Wang, B.; Liu, D.L.; Waters, C.; Yu, Q. Incorporating machine learning with biophysical model can improve the evaluation of climate extremes impacts on wheat yield in south-eastern Australia. Agric. For. Meteorol. 2019, 275, 100-113. [CrossRef]

16. Zhao, H.; Dai, T.B.; Jing, Q.; Jiang, D.; Cao, W.X. Leaf senescence and grain filling affected by post-anthesis high temperatures in two different wheat cultivars. Plant Growth Regul. 2007, 51, 149-158. [CrossRef]

17. Lobell, D.B.; Burke, M.B.; Tebaldi, C.; Mastrandrea, M.D.; Falcon, W.P.; Naylor, R.L. Prioritizing climate change adaptation needs for food security in 2030. Science 2008, 319, 607-610. [CrossRef]

18. Baker, N.R. Chlorophyll fluorescence: A probe of photosynthesis in vivo. Annu. Rev. Plant Biol. 2008, 59, 89-113. [CrossRef]

19. Porcar-Castell, A.; Tyystjarvi, E.; Atherton, J.; van der Tol, C.; Flexas, J.; Pfundel, E.E.; Moreno, J.; Frankenberg, C.; Berry, J.A. Linking chlorophyll a fluorescence to photosynthesis for remote sensing applications: Mechanisms and challenges. J. Exp. Bot. 2014, 65, 4065-4095. [CrossRef]

20. Guanter, L.; Zhang, Y.G.; Jung, M.; Joiner, J.; Voigt, M.; Berry, J.A.; Frankenberg, C.; Huete, A.R.; Zarco-Tejada, P.; Lee, J.E.; et al. Global and time-resolved monitoring of crop photosynthesis with chlorophyll fluorescence. Proc. Natl. Acad. Sci. USA 2014, 111, E1327-E1333. [CrossRef]

21. Meroni, M.; Rossini, M.; Guanter, L.; Alonso, L.; Rascher, U.; Colombo, R.; Moreno, J. Remote sensing of solar-induced chlorophyll fluorescence: Review of methods and applications. Remote Sens. Environ. 2009, 113, 2037-2051. [CrossRef]

22. Sun, Y.; Fu, R.; Dickinson, R.; Joiner, J.; Frankenberg, C.; Gu, L.H.; Xia, Y.L.; Fernando, N. Drought onset mechanisms revealed by satellite solar-induced chlorophyll fluorescence: Insights from two contrasting extreme events. J. Geophys. Res. Biogeosci. 2015, 120, 2427-2440. [CrossRef]

23. Frankenberg, C.; Fisher, J.B.; Worden, J.; Badgley, G.; Saatchi, S.S.; Lee, J.E.; Toon, G.C.; Butz, A.; Jung, M.; Kuze, A.; et al. New global observations of the terrestrial carbon cycle from GOSAT: Patterns of plant fluorescence with gross primary productivity. Geophys. Res. Lett. 2011, 38. [CrossRef]

24. Zhang, Y.G.; Guanter, L.; Berry, J.A.; Joiner, J.; van der Tol, C.; Huete, A.; Gitelson, A.; Voigt, M.; Kohler, P. Estimation of vegetation photosynthetic capacity from space-based measurements of chlorophyll fluorescence for terrestrial biosphere models. Glob. Chang. Biol. 2014, 20, 3727-3742. [CrossRef] [PubMed]

25. He, M.Z.; Kimball, J.S.; Yi, Y.H.; Running, S.; Guan, K.Y.; Jensco, K.; Maxwell, B.; Maneta, M. Impacts of the 2017 flash drought in the us northern plains informed by satellite-based evapotranspiration and solar-induced fluorescence. Environ. Res. Lett. 2019, 14. [CrossRef]

26. Guan, K.Y.; Berry, J.A.; Zhang, Y.G.; Joiner, J.; Guanter, L.; Badgley, G.; Lobell, D.B. Improving the monitoring of crop productivity using spaceborne solar-induced fluorescence. Glob. Chang. Biol. 2016, 22, 716-726. [CrossRef]

27. He, L.Y.; Magney, T.; Dutta, D.; Yin, Y.; Köhler, P.; Grossmann, K.; Stutz, J.; Dold, C.; Hatfield, J.; Guan, K.Y.; et al. From the ground to space: Using solar-induced chlorophyll fluorescence to estimate crop productivity. Geophys. Res. Lett. 2020, 47. [CrossRef]

28. Wang, X.; Qiu, B.; Li, W.; Zhang, Q. Impacts of drought and heatwave on the terrestrial ecosystem in China as revealed by satellite solar-induced chlorophyll fluorescence. Sci. Total Environ. 2019, 693. [CrossRef]

29. Challinor, A.J.; Watson, J.; Lobell, D.B.; Howden, S.M.; Smith, D.R.; Chhetri, N. A meta-analysis of crop yield under climate change and adaptation. Nat. Clim. Chang. 2014, 4, 287-291. [CrossRef] 
30. Monfreda, C.; Ramankutty, N.; Foley, J.A. Farming the planet: 2. Geographic distribution of crop areas, yields, physiological types, and net primary production in the year 2000. Glob. Biogeochem. Cycles 2008, 22. [CrossRef]

31. Sacks, W.J.; Deryng, D.; Foley, J.A.; Ramankutty, N. Crop planting dates: An analysis of global patterns. Glob. Ecol. Biogeogr. 2010, 19, 607-620. [CrossRef]

32. Siebert, S.; Ewert, F.; Rezaei, E.E.; Kage, H.; Grass, R. Impact of heat stress on crop yield-on the importance of considering canopy temperature. Environ. Res. Lett. 2014, 9. [CrossRef]

33. Rodell, M.; Houser, P.R.; Jambor, U.; Gottschalck, J.; Mitchell, K.; Meng, C.J.; Arsenault, K.; Cosgrove, B.; Radakovich, J.; Bosilovich, M.; et al. The global land data assimilation system. Bull. Am. Meteorol. Soc. 2004, 85, 381. [CrossRef]

34. Ministry of Agriculture. State of Indian Agriculture: 2015-16. 2016, New Delhi. Available online: http://eands.dacnet.nic.in/PDF/State_of_Indian_Agriculture,2015-16.pdf (accessed on 25 December 2019).

35. Yang, X.; Tang, J.W.; Mustard, J.F.; Lee, J.E.; Rossini, M.; Joiner, J.; Munger, J.W.; Kornfeld, A.; Richardson, A.D. Solar-induced chlorophyll fluorescence that correlates with canopy photosynthesis on diurnal and seasonal scales in a temperate deciduous forest. Geophys. Res. Lett. 2015, 42, 2977-2987. [CrossRef]

36. Joiner, J.; Guanter, L.; Lindstrot, R.; Voigt, M.; Vasilkov, A.P.; Middleton, E.M.; Huemmrich, K.F.; Yoshida, Y.; Frankenberg, C. Global monitoring of terrestrial chlorophyll fluorescence from moderate-spectral-resolution near-infrared satellite measurements: Methodology, simulations, and application to GOME-2. Atmos. Meas. Tech. 2013, 6, 2803-2823. [CrossRef]

37. Joiner, J.; Yoshida, Y.; Vasilkov, A.; Schaefer, K.; Jung, M.; Guanter, L.; Zhang, Y.; Garrity, S.; Middleton, E.M.; Huemmrich, K.F.; et al. The seasonal cycle of satellite chlorophyll fluorescence observations and its relationship to vegetation phenology and ecosystem atmosphere carbon exchange. Remote Sens. Environ. 2014, 152, 375-391. [CrossRef]

38. Joiner, J.; Yoshida, Y.; Guanter, L.; Middleton, E.M. New methods for the retrieval of chlorophyll red fluorescence from hyperspectral satellite instruments: Simulations and application to GOME-2 and SCIAMACHY. Atmos. Meas. Tech. 2016, 9, 3939-3967. [CrossRef]

39. Luttger, A.B.; Feike, T. Development of heat and drought related extreme weather events and their effect on winter wheat yields in Germany. Theor. Appl. Climatol. 2018, 132, 15-29. [CrossRef]

40. Rezaei, E.E.; Webber, H.; Gaiser, T.; Naab, J.; Ewert, F. Heat stress in cereals: Mechanisms and modelling. Eur. J. Agron. 2015, 64, 98-113. [CrossRef]

41. Yoshida, Y.; Joiner, J.; Tucker, C.; Berry, J.; Lee, J.E.; Walker, G.; Reichle, R.; Koster, R.; Lyapustin, A.; Wang, Y. The 2010 Russian drought impact on satellite measurements of solar-induced chlorophyll fluorescence: Insights from modeling and comparisons with parameters derived from satellite reflectances. Remote Sens. Environ. 2015, 166, 163-177. [CrossRef]

42. Sun, Y.; Frankenberg, C.; Wood, J.D.; Schimel, D.S.; Jung, M.; Guanter, L.; Drewry, D.T.; Verma, M.; Porcar-Castell, A.; Griffis, T.J.; et al. OCO-2 advances photosynthesis observation from space via solar-induced chlorophyll fluorescence. Science 2017, 358. [CrossRef] [PubMed]

43. Sun, Y.; Frankenberg, C.; Jung, M.; Joiner, J.; Guanter, L.; Kohler, P.; Magney, T. Overview of Solar-Induced chlorophyll Fluorescence (SIF) from the Orbiting Carbon Observatory-2: Retrieval, cross-mission comparison, and global monitoring for GPP. Remote Sens. Environ. 2018, 209, 808-823. [CrossRef]

44. Smith, W.K.; Biederman, J.A.; Scott, R.L.; Moore, D.J.P.; He, M.; Kimball, J.S.; Yan, D.; Hudson, A.; Barnes, M.L.; MacBean, N.; et al. Chlorophyll Fluorescence Better Captures Seasonal and Interannual Gross Primary Productivity Dynamics Across Dryland Ecosystems of Southwestern North America. Geophys. Res. Lett. 2018, 45, 748-757. [CrossRef]

45. Qian, X.; Qiu, B.; Zhang, Y.G. Widespread Decline in Vegetation Photosynthesis in Southeast Asia Due to the Prolonged Drought During the 2015/2016 El Nino. Remote Sens. 2019, 11, 910. [CrossRef]

46. Luo, X.; Keenan, T.F.; Fisher, J.B.; Jiménez-Muñoz, J.C.; Chen, J.M.; Jiang, C.; Ju, W.; Perakalapudi, N.V.; Ryu, Y.; Tadić, J.M. The impact of the 2015/2016 El Niño on global photosynthesis using satellite remote sensing. Philos. Trans. R. Soc. B 2018, 373, 20170409. [CrossRef] [PubMed]

47. Yu, L.; Wen, J.; Chang, C.Y.; Frankenberg, C.; Sun, Y. High-resolution global contiguous SIF of OCO-2. Geophys. Res. Lett. 2019, 46, 1449-1458. [CrossRef] 
48. Louis, J.; Ounis, A.; Ducruet, J.M.; Evain, S.; Laurila, T.; Thum, T.; Aurela, M.; Wingsle, G.; Alonso, L.; Pedros, R.; et al. Remote sensing of sunlight-induced chlorophyll fluorescence and reflectance of Scots pine in the boreal forest during spring recovery. Remote Sens. Environ. 2005, 96,37-48. [CrossRef]

49. Zhang, Y.G.; Guanter, L.; Joiner, J.; Song, L.; Guan, K.Y. Spatially-explicit monitoring of crop photosynthetic capacity through the use of space-based chlorophyll fluorescence data. Remote Sens. Environ. 2018, 210, 362-374. [CrossRef]

50. Peng, B.; Guan, K.Y.; Zhou, W.; Jiang, C.Y.; Frankenberg, C.; Sun, Y.; He, L.Y.; Köhler, P. Assessing the benefit of satellite-based Solar-Induced Chlorophyll Fluorescence in crop yield prediction. Int. J. Appl. Earth Obs. Geoinf. 2020, 90. [CrossRef]

(C) 2020 by the authors. Licensee MDPI, Basel, Switzerland. This article is an open access article distributed under the terms and conditions of the Creative Commons Attribution (CC BY) license (http://creativecommons.org/licenses/by/4.0/). 